\title{
A Study on the Job Engagement of Company Employees
}

\author{
Ying Kong \\ School of Education Science, Qufu Normal University \\ Qufu 273165, China \\ E-mail: kongying1986@yeah.net
}

This paper is financed by Soft-science Project in Shandong Province: research on the improvement of the competition competence of High-tech leading enterprises in Shandong. Project Number: 2008RKA198)

\begin{abstract}
Purpose The present paper, based on relative studies done both at home and abroad, intends to investigate the relationships between individual characteristics of the employees in the company and their job engagement. Methodology by using the UWES (Utreeht Work Engagement Scale) Result The relevance between company employees' individual characteristics and the variables of job engagement is significant. The regression analysis further finds out that the regression is significant between company employees' individual characteristics and the dimensions (vigor, dedication, and absorption) of job engagement. In addition, gender and length of working can predict the degree of employees' engagement into working. Conclusion employees' individual characteristics studied in the present paper have an effect on their job engagement.
\end{abstract}

Keywords: Job engagement, Vigor, Dedication, Absorption

With the development of Positive Psychology and Positive Organizational Behavior, the long-ignored human virtues, such as the strength and positivity of the members in an organization, and positive mental abilities are attracting more and more attention. Within this context, job engagement, as the opposite of job disengagement, becomes the new research focus of scholars.

Kahn (1990) puts forward the concept of "personal engagement" for the first time. And he defines personal engagement as the harnessing of organization members' selves to their work roles (Kahn, 1990: 694). From the point of view of Kahn, self and work role exist in some dynamic and negotiable relation: when engaged deeper in his or her job, a person both drives personal energies into role behaviors (self-employment) and displays the self within the role (self-expression); in the opposite condition, the individual uncouples self from role, avoids creating job achievement, and displays an evacuation from role obligations. Scholars, such as Schaufeli, extend Kahn's concept of job engagement in another way. They define job engagement as a full state with persistent and positive moods and motivations, with vigor, dedication, and absorption as its major features.

Based on studies done both at home and aboard, the present author attempts to investigate the effect of employees' individual characteristics on their job engagement.

\section{Subjects and Methods}

\subsection{Subjects}

The current study selected 300 employees randomly from three companies to fill in the questionnaires. 248 questionnaires were recovered, reaching a response rate of $83 \%$. Among the three companies one is located in the urban area, and the other two are from the countryside. Of all the employees, 182 were male ones, occupying 52\%; and 118 female employees, with a percentage of $48 \%$.

\subsection{Instruments}

The measurement of job engagement was conducted with the UWES (Utreeht work engagement scale), which was designed by Schaufeli. The scale involves three factors: vigor, dedication, and absorption. Zhang Yiwen, a scholar in China, has proved that the UWES deserves a high degree of reliability and validity . 


\subsection{Data analysis}

SPSS 11.5 was used for analyzing the data in the present study.

\section{Results}

\subsection{The differences in job engagement between the employees in company with different characteristics}

First of all, a comparison was done to reveal the differences in job engagement between employees with different characteristics. The compound analysis $(2 \times 2 \times 6)$ was used for analyzing the three factors: gender, marital status, and length of working (see Table 1).

\section{Insert Table 1 here}

Table 1 shows that the difference between male and female employees in their job engagement is manifested mainly on the dimension of dedication. The interaction between gender and marital status has a significant difference in the dimensions of vigor and dedication of job engagement.

\subsection{The differences in job engagement between male and female company employees}

A further investigation of the scores gained by male and female employees in their job engagement shows that male employees have higher scores over female ones on the dimension of vigor and absorption while female employees gain more scores than male ones on the dimension of dedication.

\section{Insert Table 2 here}

\subsection{The differences in job engagement between company employees with different marital status}

From the above analysis, it can be seen that the interaction between company employees' gender and their marital status has a significant difference in the dimensions of vigor and dedication of job engagement. A further analysis of the scores gained by company employees in their job engagement on the three dimensions shows: unmarried employees have higher scores than those married ones on all the three dimensions of job engagement, esp. on the dimensions of vigor and dedication.

\section{Insert Table 3 here}

\subsection{The differences in job engagement between company employees with different length of working}

A further analysis of the scores gained by the employees in the company of different length of working shows that company employees with $0 \sim 5$ years of working gain the highest scores on all the three dimensions. However, there is a fall in the job engagement of employees who have a length of $6 \sim 10$ years of working experience. And there is a rise in job engagement of employees with 11 15 years of working. Employees who have 16 20 years of working experience gain the lowest scores on the dimensions of dedication and absorption.

\section{Insert Table 4 here}

\section{Discussions}

The results of the present study show that there exist differences in job engagement between male and female employees in the company, esp. on the dimension of dedication. Female employees value more their jobs than male ones. Male employees gain higher scores on the dimensions of vigor and absorption than female ones, which can be partly explained by the fact that men are generally more vigorous than women.

Unmarried employees gain higher scores than married employees on all the three dimensions, which may be explained by the fact that unmarried employees have more time and energy to spend on job. Generally speaking, due to having a short time in working, male employees feel refreshed when they work, and this will strengthen their engagement in working.

Employees with a length of working for 0 5 years gain higher scores than those in other groups in job engagement on all the three dimensions. Usually, the employees who have just begun working have a fresh feeling towards their job, and are full of energy. There appears a fall in job engagement of employees with a length of working for $6 \sim 10$ years. The two possible reasons: one is that they feel a bit tired after a period of high-engagement into working; another reason is that employees in this group have established their own families, which makes them distribute part of their energy into their families. Thus, it is understandable that there appears a fall in their job engagement. Then, a rise appears in job engagement of the employees. On the whole, after 6 years of working, there will appear a fall-rise curve in the job engagement of company employees.

\section{Conclusions and Implications}

Through the analysis of the job engagement of 248 employees from the three fatories, the present study draws the following conclusions:

(1) Female employees dedicate significantly more than male employees in their job engagement. Create reasonable 
atmosphere and conditions for employees, make them involved in job and experience success and happiness, thus to make them more devoted into working.

(2) The strength of unmarried employees' full of energy and deep engagement into working should be made good use of. Efforts should be made to create a harmonious human relationships and a good cultural atmosphere in factory. In addition, the job engagement of married employees should be strengthened.

(3) High pertinence should be strengthened according to the different length of working of the employees. The construction of company culture should be favorable for relieving the tiredness and pressure of working for the employees, so as to make them more dedicated into working.

\section{References}

Kahn WA. (1990). Psychological Conditions of Personal Engagement and Disengagement at Work. Academy of Management Journal, 33(4): 692-724.

Li Jinbo, Xu Baihua, \& Chen, Jianming. (2006). The Effect of Organizational Factors on Job Engagement. Chinese Journal of Applied Psychology, 12(2): 176-181.

Li, Rui \& Ling, Wen. (2007). A Review of the Research on Work/Job Engagement. Advances in Psychological Science, 15 (2): 366-372.

Saleh, S. D. \& Hosek, J. (1976). Job involvement: Concept and measurement. Academy of Management Journal, 19(2): 213-224.

Schaufeli W. B., Salanova M, Gonza RV, et al. (2002). The Measurement of Engagement and Burn out: A Confirmative Analytic Approach. Journal of Happiness Studies, 3(1): 71-92.

Sheng, Jiansen. (2006). Teachers, Job Involvement: Its Structure and Influencing Factors. Psychological Development and Education, (2): 108-112.

Zhang, Yiwen \& Gan Yiqun. (2005). The Chinese Version of Utrecht Work Engagement Scale: An Examination of Reliability and Validity. Chinese Journal of Clinical Psychology, 13(3): 268-271.

Table 1. The compound analysis of the job engagement of company employees with different gender, marital status and length of working

\begin{tabular}{lccc}
\hline Source of variance & vigor & dedication & absorption \\
\hline gender & 1.249 & $4.138^{*}$ & 1.214 \\
marital status & 0.297 & 0.028 & 0.005 \\
length of working & 0.306 & 0.559 & 1.225 \\
gender $\times$ marital status & $4.097^{*}$ & $5.301^{*}$ & 2.690 \\
gender $\times$ marital status & 1.373 & 2.087 & 2.152 \\
marital status $\times$ length of working & 0.432 & 0.620 & 1.099 \\
gender $\times$ marital status $\times$ length of working & 0.789 & 0.379 & 0.013 \\
\hline
\end{tabular}

Notes: " $\times$ " stands for the interaction; * $\mathrm{p}<0.05$

Table 2. A comparison of job engagement between male and female employees

\begin{tabular}{lcc}
\hline & Male employees M (SD) & Female employees M (SD) \\
\hline vigor & $29.17(6.72)$ & $27.89(6.91)$ \\
dedication & $24.92(6.79)$ & $25.32(6.19)$ \\
absorption & $25.28(5.70)$ & $25.09(5.53)$ \\
\hline
\end{tabular}


Table 3. A comparison of job engagement between employees of different marital status

\begin{tabular}{lcc}
\hline & Unmarried employees M (SD) & Married employees M (SD) \\
\hline vigor & $29.53(7.32)$ & $28.40(6.77)$ \\
dedication & $25.69(6.48)$ & $24.93(6.61)$ \\
absorption & $25.33(5.17)$ & $25.18(5.73)$ \\
\hline
\end{tabular}

Table 4. A comparison of job engagement between employees of different length of working

\begin{tabular}{llll}
\hline & vigor M (SD) & dedication M (SD) & absorption M (SD) \\
\hline 0-5 years (group1) & $30.00(6.22)$ & $26.58(5.89)$ & $26.02(5.25)$ \\
6-10 years (group2) & $27.84(7.50)$ & $24.48(7.17)$ & $25.03(5.92)$ \\
$\mathbf{1 1 - 1 5}$ years (group 3) & $28.28(6.53)$ & $25.46(6.52)$ & $25.26(5.29)$ \\
$\mathbf{1 6 - 2 0}$ years (group 4) & $28.31(7.55)$ & $23.69(6.21)$ & $24.25(6.73)$ \\
$\mathbf{2 1 - 2 5}$ years (group 5) & $29.00(6.10)$ & $24.42(7.40)$ & $25.53(6.26)$ \\
over 25 years (group 6) & $28.57(7.41)$ & $25.14(6.43)$ & $25.07(4.94)$ \\
\hline
\end{tabular}

